\title{
A significant association between examination results and self-satisfaction with English language proficiency: preliminary findings among pre-clinical undergraduates
}

\author{
Madushika Wijesundara' , Chamindi Wijerathna' ${ }^{1}$ Kasun Wijerathna', Rasangi Wijerathna', Srimali Wijethunga',
} Ashan Wijewardana', Anuprabha Wickramasinghe ${ }^{2}$ and Devarajan Rathish ${ }^{3^{*}}$ (1)

\begin{abstract}
Objectives: Learning methods and other related factors influence the success of medical undergraduates. This study aims at finding factors associated with the end of pre-clinical stream examination results among medical undergraduates of the Rajarata University of Sri Lanka. The results of this study will inform the tutors to plan and implement teaching methods as well as to guide the social welfare of the undergraduates. In general, we believe this study has the potential to improve the medical undergraduate's academic performance.

Results: Eighty-six per cent (112/130) of medical undergraduates have passed the examination and rest was referred. Logistic regression revealed a significant association between examination results and self-satisfaction for English language proficiency $(P=0.048)$. Passing the examination was more likely with high self-satisfaction for English language proficiency [odds ratio $=6.063(95 \% \mathrm{Cl} 1.014$ to 36.249$)$ ]. Also, a significant association between obtaining a class at the examination and using peer-revision notes $(P=0.019)$ was revealed. Obtaining a class at the examination was less likely with the frequent use of peer-revision notes [odds ratio $=0.228$ ( $95 \% \mathrm{Cl} 0.066$ to 0.790)].
\end{abstract}

Keywords: Medical education, Undergraduates, English proficiency, Peer-revision notes

\section{Introduction}

Undergraduates entering medical schools are selected through preceding higher academic performances. Although previous academic performance is a suitable prognosticator of achievements at the medical school, it is not a perfect predictor [1]. Reflective and active learning styles were found to be more common among preclinical and clinical undergraduates [2]. Career concerns and goal orientation were related to higher academic performances [3]. Nevertheless, completion of the medical

\footnotetext{
*Correspondence: rathishdeva@gmail.com

${ }^{3}$ Department of Pharmacology, Faculty of Medicine and Allied Sciences,

Rajarata University of Sri Lanka, Saliyapura, Sri Lanka

Full list of author information is available at the end of the article
}

course is not without the involvement of stress [4-6]. However, self-directed learning has been positively associated with knowledge acquisition [7].

Various methods are used by medical undergraduates to prepare for examinations $[2,8,9]$. Reproducing and meaning orientation has its influence on the success of medical undergraduates [10]. Learning styles vary and are subjective. Also, these may be associated with individual comprehension and predict success at examinations [11]. It is a complex task to figure out the study method that best suits an individual. Tutors should be able to cater knowledge according to different learning styles [2]. Most undergraduates use deep and strategic learning styles, while the latter leads to higher examination results [11]. Medical undergraduates prefer problem-based 
learning than traditional lectures to enhance their learning outcomes [12]. Undergraduates have acknowledged team-based learning and learning from peers [13]. Preclinical academic achievements is a predictor of better performance during the later years at medical school [14]. Therefore, good learning methods introduced during the pre-clinical stage could enhance medical undergraduate's future performance.

There are factors other than learning methods that can affect the undergraduate's ability to be an effective learner [15-17]. Positive and negative emotions are paramount in successful learning [18]. Some undergraduates undergo severe stress in completing the course $[4,15$, 19]. Majority experience stress related to their academic work and examinations [20,21]. Stress is highly recorded, especially during the first year [22]. It is a challenging job for them to navigate through the initial years at the medical school. Adequate sleep, less time on social media, and weekend academic work has shown to achieve higher academic performance [16]. Lack of awareness on learning methods, poor physical fitness, inadequate extracurricular activities, psycho-social issues, lack of sleep and unhealthy food practices are some contributive factors for stress and the subsequent academic failure [23, 24]. Change in the medium of learning and living in hostels were also associated with academic related stress [25].

This study was aimed at finding the factors associated with the end of pre-clinical stream examination results of the medical undergraduates of the Rajarata University of Sri Lanka. An important insight is expected which will inform the future generation of undergraduates in effective learning.

\section{Main text \\ Methods}

A descriptive cross-sectional study was conducted among the pre-clinical stream medical undergraduates of the Faculty of Medicine and Allied Sciences, Rajarata University of Sri Lanka. This latest medical school of Sri Lanka was established in 2006. It is situated at Anuradhapura, a rural district of Sri Lanka [26], $210 \mathrm{~km}$ away from the capital city of Colombo. Medical education at this faculty is conducted in English medium. Around 900-1000 undergraduates are on the roll at a given time and are divided into pre-clinical, para-clinical and clinical streams. The pre-clinical stream includes the first and second year teaching of anatomy, biochemistry and physiology. Lectures, practical sessions, tutorials and dissections are methods used for teaching and learning activities. The end of pre-clinical stream examination is a bar examination to enter the para-clinical stream, and a maximum of four attempts are allowed. It includes theory (multiple choice and short essay questions) and practical examinations. All undergraduates who received their end of pre-clinical stream main examination results in the year 2016 were approached soon after the release of the results and 142 out of 182 (78\%) participated in the study.

A self-administered questionnaire was used to obtain data for examination results (outcome variable) and the following independent variables: (1) revision of lecture handouts before the beginning of the study leave, (2) using textbooks, peer-revision notes and online resources, (3) having an effective study group, (4) selfpractice of past paper questions, (5) discussing past paper questions in a study group, (6) sense of interference to academic work due to stress and psycho-social issues, (7) duration of uninterrupted sleep and (8) self-satisfaction with time management, English language proficiency, physical fitness, leisure activity, family support, financial support and accommodation. Lecture hand-outs are usually of the whole lecture which includes the detailed subject matter and the list of resources which the undergraduates should refer. Response categories for each of the variables are shown in Tables 1 and 2. The questionnaire was pre-tested among five undergraduates to improve its content, language and sequence.

Explaining the study, obtaining verbal informed consent and data collection were done by the first six authors. All necessary measures were taken to preserve participant's privacy and confidentiality. Permanent lecturers at the faculty avoided obtaining consent or collection of the questionnaires to avoid coercion. Data were entered into a Microsoft Excel sheet for analysis (Additional file 1). Descriptive statistics were used to describe data. Undergraduates were grouped into two: those who passed and those who referred at the examination. Also, those who passed the examination were grouped into two: passed without a class and passed with a class at the examination. Logistic regression was performed to determine the significant association between variables of interest and the examination results $(\mathrm{P}<0.05)$. Odds ratios with $95 \%$ confidence interval were presented for each variable of interest.

\section{Results}

Out of the 142 undergraduates who participated in the study, 12 were omitted from analysis due to missing data. Eighty-six per cent (112/130) have passed the examination and rest was referred. Out of those who passed, 26\% (29/112) had a class.

Eighty-nine per cent (101/113) of undergraduates who had high self-satisfaction for English language proficiency passed the exam, in comparison to 65\% (11/17) of those who thought to have less self-satisfaction for English language proficiency. Logistic regression revealed a significant association between examination results 
Table 1 Examination results against the variables of interest (passing the examination)

\begin{tabular}{|c|c|c|c|c|c|c|}
\hline \multirow[t]{2}{*}{ Item } & \multirow[t]{2}{*}{ Description } & \multirow[t]{2}{*}{ Passed } & \multirow[t]{2}{*}{ Referred } & \multicolumn{3}{|c|}{ Logistic regression } \\
\hline & & & & $P$ value & Coefficient & Odds ratio $(95 \% \mathrm{Cl})$ \\
\hline \multirow[t]{2}{*}{ 1. Revising lecture notes } & Before study leave & 100 & 12 & 0.177 & 1.307 & $3.694(0.555-24.587)$ \\
\hline & During study leave & 12 & 6 & & & \\
\hline \multirow[t]{2}{*}{ 2. Using textbooks } & Frequently & 106 & 14 & 0.443 & 0.951 & $2.587(0.228-29.396)$ \\
\hline & Occasionally & 6 & 4 & & & \\
\hline \multirow[t]{2}{*}{ 3. Using peer-revision notes } & Frequently & 94 & 15 & 0.754 & 0.280 & $1.323(0.230-7.606)$ \\
\hline & Occasionally & 18 & 3 & & & \\
\hline \multirow[t]{2}{*}{ 4. Using online resources } & Frequently & 56 & 10 & 0.328 & -0.710 & $0.492(0.119-2.039)$ \\
\hline & Occasionally & 56 & 8 & & & \\
\hline \multirow[t]{2}{*}{ 5. Effective study group } & $\mathrm{Had}$ & 24 & 3 & 0.513 & -0.585 & $0.557(0.096-3.219)$ \\
\hline & Not had & 88 & 15 & & & \\
\hline \multirow[t]{2}{*}{ 6. Self-practice of past multiple-choice questions } & Frequently & 98 & 14 & 0.391 & -1.035 & $0.355(0.033-3.779)$ \\
\hline & Occasionally & 14 & 4 & & & \\
\hline \multirow{2}{*}{ 7. Self-practice of past short essay questions } & Frequently & 98 & 12 & 0.081 & 1.756 & $5.787(0.806-41.524)$ \\
\hline & Occasionally & 14 & 6 & & & \\
\hline \multirow[t]{2}{*}{ 8. Discussing past paper questions in a group } & Frequently & 70 & 12 & 0.455 & -0.605 & $0.546(0.112-2.670)$ \\
\hline & Occasionally & 42 & 6 & & & \\
\hline \multirow[t]{2}{*}{ 9. Stress related interference to academic work } & Minimal & 27 & 4 & 0.106 & 1.539 & $4.661(0.720-30.159)$ \\
\hline & Substantial & 85 & 14 & & & \\
\hline \multirow[t]{2}{*}{ 10. Psycho-social issues related interference to academic work } & Minimal & 60 & 14 & 0.545 & -0.472 & $0.623(0.135-2.882)$ \\
\hline & Substantial & 52 & 4 & & & \\
\hline \multirow[t]{2}{*}{ 11. Uninterrupted sleep } & $\geq 8 \mathrm{~h}$ & 14 & 3 & 0.170 & -1.573 & $0.208(0.022-1.960)$ \\
\hline & $<8 \mathrm{~h}$ & 98 & 15 & & & \\
\hline \multirow[t]{2}{*}{ 12. Satisfaction with time management skills } & High & 61 & 04 & 0.081 & -1.392 & $0.249(0.052-1.188)$ \\
\hline & Less & 51 & 14 & & & \\
\hline \multirow[t]{2}{*}{ 13. Satisfaction with English language proficiency } & High & 101 & 12 & 0.048 & 1.802 & $6.063(1.014-36.249)$ \\
\hline & Less & 11 & 06 & & & \\
\hline \multirow[t]{2}{*}{ 14. Satisfaction with physical fitness } & High & 84 & 12 & 0.798 & 0.212 & $1.236(0.243-6.289)$ \\
\hline & Less & 28 & 6 & & & \\
\hline \multirow[t]{2}{*}{ 15. Satisfaction with leisure activities } & High & 55 & 8 & 0.203 & 0.916 & $2.499(0.610-10.247)$ \\
\hline & Less & 57 & 10 & & & \\
\hline \multirow[t]{2}{*}{ 16. Satisfaction with family support } & High & 104 & 18 & 0.999 & -21.255 & 0.000 \\
\hline & Less & 8 & 0 & & & \\
\hline \multirow[t]{2}{*}{ 17. Satisfaction with financial support } & High & 102 & 16 & 0.257 & -1.623 & $0.197(0.012-3.256)$ \\
\hline & Less & 10 & 2 & & & \\
\hline \multirow[t]{2}{*}{ 18. Satisfaction with accommodation } & High & 72 & 15 & 0.081 & -1.632 & $0.195(0.031-1.221)$ \\
\hline & Less & 40 & 3 & & & \\
\hline
\end{tabular}

Italic values indicate significance with a $p$-value of $<0.05$

and self-satisfaction with English language proficiency $(\mathrm{P}=0.048)$. A positive coefficient (1.802) indicated that passing the examination was more likely with high selfsatisfaction for English language proficiency. The above was further confirmed by an odds ratio of 6.063 (95\% CI 1.014 to 36.249 ) for high self-satisfaction for English language proficiency.

Logistic regression revealed no significant association between examination results (passed and referred) and the following factors of interest: revision of lecture handouts before the beginning of the study leave, using textbooks, peer-revision notes and online resources, having an effective study group, self-practice of past paper questions, discussing past paper questions in a study group, sense of interference to academic work due to stress and psycho-social issues, duration of uninterrupted sleep and self-satisfaction with time management, physical fitness, leisure activity, family support, financial support and accommodation (Table 1). 
Table 2 Examination results against the variables of interest (obtaining a class at the examination)

\begin{tabular}{|c|c|c|c|c|c|c|}
\hline \multirow[t]{2}{*}{ Item } & \multirow[t]{2}{*}{ Description } & \multirow{2}{*}{$\begin{array}{l}\text { Passed } \\
\text { without } \\
\text { a class }\end{array}$} & \multirow{2}{*}{$\begin{array}{l}\text { Passed } \\
\text { with a class }\end{array}$} & \multicolumn{3}{|c|}{ Logistic regression } \\
\hline & & & & $P$ value & Coefficient & Odds ratio $(95 \% \mathrm{Cl})$ \\
\hline \multirow[t]{2}{*}{ 1. Revising lecture notes } & Before study leave & 75 & 25 & 0.249 & -1.041 & $0.353(0.060-2.073)$ \\
\hline & During study leave & 08 & 04 & & & \\
\hline \multirow[t]{2}{*}{ 2. Using textbooks } & Frequently & 78 & 28 & 0.561 & -1.031 & $0.357(0.011-11.496)$ \\
\hline & Occasionally & 05 & 01 & & & \\
\hline \multirow[t]{2}{*}{ 3. Using peer-revision notes } & Frequently & 73 & 21 & 0.020 & -1.480 & $0.228(0.066-0.790)$ \\
\hline & Occasionally & 10 & 08 & & & \\
\hline \multirow[t]{2}{*}{ 4. Using online resources } & Frequently & 43 & 13 & 0.827 & -0.118 & $0.889(0.308-2.564)$ \\
\hline & Occasionally & 40 & 16 & & & \\
\hline \multirow[t]{2}{*}{ 5. Effective study group } & $\mathrm{Had}$ & 18 & 06 & 0.958 & -0.035 & $0.965(0.259-3.602)$ \\
\hline & Not had & 65 & 23 & & & \\
\hline \multirow[t]{2}{*}{ 6. Self-practice of past multiple-choice questions } & Frequently & 70 & 28 & 0.190 & 2.143 & $8.523(0.346-209.809)$ \\
\hline & Occasionally & 13 & 01 & & & \\
\hline \multirow[t]{2}{*}{ 7. Self-practice of past short essay questions } & Frequently & 71 & 27 & 0.945 & 0.072 & $1.074(0.141-8.168)$ \\
\hline & Occasionally & 12 & 02 & & & \\
\hline \multirow[t]{2}{*}{ 8. Discussing past paper questions in a group } & Frequently & 51 & 19 & 0.888 & 0.079 & $1.082(0.363-3.223)$ \\
\hline & Occasionally & 32 & 10 & & & \\
\hline \multirow[t]{2}{*}{ 9. Stress related interference to academic work } & Minimal & 20 & 07 & 0.455 & -0.507 & $0.603(0.160-2.274)$ \\
\hline & Substantial & 63 & 22 & & & \\
\hline \multirow{2}{*}{$\begin{array}{l}\text { 10. Psycho-social issues related interference to } \\
\text { academic work }\end{array}$} & Minimal & 42 & 18 & 0.252 & 0.673 & $1.961(0.619-6.209)$ \\
\hline & Substantial & 41 & 11 & & & \\
\hline \multirow[t]{2}{*}{ 11. Uninterrupted sleep } & $\geq 8 \mathrm{~h}$ & 09 & 05 & 0.072 & 1.423 & $4.148(0.878-19.595)$ \\
\hline & $<8 \mathrm{~h}$ & 74 & 24 & & & \\
\hline \multirow[t]{2}{*}{ 12. Satisfaction with time management skills } & High & 39 & 12 & 0.397 & -0.490 & $0.612(0.197-1.903)$ \\
\hline & Less & 44 & 17 & & & \\
\hline \multirow[t]{2}{*}{ 13. Satisfaction with English language proficiency } & High & 74 & 27 & 0.522 & 0.640 & $1.896(0.267-13.454)$ \\
\hline & Less & 09 & 02 & & & \\
\hline \multirow[t]{2}{*}{ 14. Satisfaction with physical fitness } & High & 60 & 24 & 0.820 & 0.142 & $1.153(0.339-3.916)$ \\
\hline & Less & 23 & 05 & & & \\
\hline \multirow[t]{2}{*}{ 15. Satisfaction with leisure activities } & High & 38 & 17 & 0.405 & 0.457 & $1.580(0.538-4.639)$ \\
\hline & Less & 45 & 12 & & & \\
\hline \multirow[t]{2}{*}{ 16. Satisfaction with family support } & High & 76 & 28 & 0.301 & 1.416 & $4.121(0.281-60.468)$ \\
\hline & Less & 07 & 01 & & & \\
\hline \multirow[t]{2}{*}{ 17. Satisfaction with financial support } & High & 74 & 28 & 0.576 & 0.717 & $2.049(0.166-25.340)$ \\
\hline & Less & 09 & 01 & & & \\
\hline \multirow[t]{2}{*}{ 18. Satisfaction with accommodation } & High & 51 & 21 & 0.635 & 0.298 & $1.348(0.393-4.624)$ \\
\hline & Less & 32 & 08 & & & \\
\hline
\end{tabular}

Italic values indicate significance with a p-value of $<0.05$

Forty-four per cent (08/18) of undergraduates who occasionally used peer-revision notes had a class at the examination, in comparison to $22 \%$ (21/94) of those who frequently used peer-revision notes. Logistic regression revealed a significant association between obtaining class at the examination and using peer-revision notes $(P=0.019)$. A negative coefficient $(-1.480)$ indicated that obtaining of a class was less likely with the frequent use of peer-revision notes. The above was further confirmed by an odds ratio of 0.228 ( $95 \%$ CI 0.066 to 0.790 ) for frequent use of peer-revision notes. Logistic regression revealed no significant association between obtaining a class at the examination and the rest of the factors of interest considered in this study (Table 2).

\section{Discussion}

Examination results were significantly associated with high self-satisfaction for English language proficiency. 
Previous evidence suggests that a change in medium of learning was associated with academic related stress [25]. Majority of the Sri Lankan medical undergraduates face a change in medium of learning when they enter the university after completion of their schooling. Medical teaching should promote English language proficiency which would help improve the performance of medical undergraduates at examinations.

Using peer-revision notes is popular learning methods among medical undergraduates. However, obtaining of a class was less likely with the frequent use of peerrevision notes. The above finding highlights the need for strict scrutiny of these peer-revision notes. Nevertheless, the use of textbooks and online resources revealed no significant association with the examination results. Also, interference by psycho-social issues had no significant association with academic performance. Inappropriate learning methods and psycho-social issues were shown to be contributive factors for academic stress and subsequent academic failure in prior studies [23, 24]. In contrary to previous literature [16], the duration of uninterrupted sleep also failed to reveal any association with academic performance. It is also surprising to note that having an effective study group and practising of past papers did not influence the examination results.

\section{Limitations}

Findings of a cross-sectional study conducted amongst a single batch of undergraduates of a particular medical school cannot establish a causal association and neither it could be generalised. A national survey at all other medical schools of Sri Lanka would be ideal. However, present data are unique as it was from a medical school located in a rural region, which was the latest to be established in the country. The data on variables of interest were collected following the release of the examination results. However, it would have been ideal if it were collected before the release of the results and subsequently tallied with the examination results. Nevertheless, this is methodologically challenging especially with de-identification and could have led to a high proportion of drop-outs.

\section{Additional file}

Additional file 1. Factors associated with the end of pre-clinical stream examination results of medical undergraduates.

\section{Authors' contributions}

All authors were involved in developing the study idea and designing the study. M Wijesundara, C Wijerathna, KWijerathna, R Wijerathna, SWijethunga and A Wijewardana were involved in data collection. M Wijesundara, C Wijerathna, K Wijerathna, R Wijerathna, S Wijethunga, A Wijewardana and D Rathish were involved in data analysis. All authors were involved in the interpretation of data. M Wijesundara, C Wijerathna, K Wijerathna, R Wijerathna, S Wijethunga and A Wijewardana drafted the manuscript and D Rathish; A Wickramasinghe critically revised it. All authors read and approved the final manuscript.

\section{Author details}

${ }_{1}^{1}$ Faculty of Medicine and Allied Sciences, Rajarata University of Sri Lanka, Saliyapura, Sri Lanka. ${ }^{2}$ Department of Psychiatry, Faculty of Medicine and Allied Sciences, Rajarata University of Sri Lanka, Saliyapura, Sri Lanka. ${ }^{3}$ Department of Pharmacology, Faculty of Medicine and Allied Sciences, Rajarata University of Sri Lanka, Saliyapura, Sri Lanka.

\section{Acknowledgements}

Authors extend their gratitude to the Undergraduate Research Project 2016, Faculty of Medicine and Allied Sciences, Rajarata University of Sri Lanka for the guidance and help provided.

\section{Competing interests}

The authors declare that they have no competing interests.

\section{Availability of data and materials}

All data generated or analysed during this study are included in this published article (and its additional file).

\section{Consent for publication}

Not applicable.

\section{Ethics approval and consent to participate}

Ethical clearance was obtained from the Ethics Review Committee, Faculty of Medicine and Allied Sciences, Rajarata University of Sri Lanka (ERC/2016/58). Informed written consent to participate was obtained from all participants.

\section{Funding}

The study was self-funded.

\section{Publisher's Note}

Springer Nature remains neutral with regard to jurisdictional claims in published maps and institutional affiliations.

Received: 19 June 2018 Accepted: 2 November 2018

Published online: 12 November 2018

\section{References}

1. Ferguson E. Factors associated with success in medical school: systematic review of the literature. BMJ. 2002;324(7343):952-7.

2. Jiraporncharoen W, Angkurawaranon C, Chockjamsai M, Deesomchok A, Euathrongchit J. Learning styles and academic achievement among undergraduate medical students in Thailand. J Educ Eval Health Prof. 2015;12:38.

3. Yousefi Z, Abedi M, Baghban I, Eatemadi O, Abedi A. Personal and situational variables, and career concerns: predicting career adaptability in young adults. Span J Psychol. 2011;14(1):263-71.

4. Dyrbye LN, Thomas MR, Shanafelt TD. Systematic review of depression, anxiety, and other indicators of psychological distress among U.S. and Canadian medical students. Acad Med. 2006;81:354-73.

5. Good medical practice: the duties of a doctor registered with the general medical council. Med Educ [Internet]. 2001;35(s1):70-8. http://doi.wiley .com/10.1046/j.1365-2923.2001.00009.x.

6. Yen Yee L, Yusoff MSB. Prevalence and sources of stress among medical students in Universiti Sains Malaysia and Universiteit Maastricht. Educ Med J. 2013;5(4):34-41.

7. McDonald FS, Zeger SL, Kolars JC. Factors associated with medical knowledge acquisition during internal medicine residency. J Gen Intern Med. 2007;22(7):962-8

8. Kharb P, Samanta PP, Jindal M, Singh V. The learning styles and the preferred teaching-learning strategies of first year medical students. J Clin Diagn Res. 2013;7(6):1089-92.

9. Buşan A-M. Learning styles of medical students-implications in education. Curr Health Sci J. 2014;40(2):104-10. 
10. Newble DI, Gordon MI. The learning style of medical students. Med Educ. 1985;19(1):3-8.

11. Shankar PR, Dubey AK, Binu VS, Subish P, Deshpande VY. Learning styles of preclinical students in a medical college in western Nepal. Kathmandu Univ Med J. 2006:4(3):390-5.

12. Ibrahim NK, Banjar S, Al-Ghamdi A, Al-Darmasi M, Khoja A, Turkistani J, et al. Medical students' preference of problem-based learning or traditional lectures in King Abdulaziz University, Jeddah, Saudi Arabia. Ann Saudi Med. 2014;34(2):128-33.

13. Vasan NS, DeFouw DO, Holland BK. Modified use of team-based learning for effective delivery of medical gross anatomy and embryology. Anat Sci Educ. 2008;1 (1):3-9.

14. Alfayez SF, Strand DA, Carline JD. Academic, social and cultural factors influencing medical school grade performance. Med Educ. 1990;24(3):230-8.

15. Ahmad A, Abulaban A, Al Shawwa L, Merdad A, Baghlaf S, Abu-shanab $J$, et al. Factors potentially influencing academic performance among medical students. Adv Med Educ Pract. 2015;6:65.

16. Mohammed OS, Alyoussef AA, Mirghani HO, Ahmed MA, Elbadawi AS Impact of lifestyle on academic performance of medical students at University of Tabuk. Indian J Appl Res. 2015;5(7):131-3.

17. Nechita F, Nechita D, Pîrlog MC, Rogoveanu I. Stress in medical students. Rom J Morphol Embryol. 2014;55:1263-6.
18. Reeve CL, Bonaccio S, Winford EC. Cognitive ability, exam-related emotions and exam performance: a field study in a college setting. Contemp Educ Psychol. 2014;39(2):124-33.

19. Sherina MS, Rampal L, Kaneson N. Psychological stress among undergraduate medical students. Med J Malaysia. 2004;59(2):207-11.

20. Saipanish R. Stress among medical students in a Thai medical school. Med Teach. 2003;25(5):502-6.

21. Loubir DB, Serhier Z, Diouny S, Battas O, Agoub M, Othmani MB. Prevalence of stress in Casablanca medical students: a cross-sectional study. Pan Afr Med J. 2014;19:149.

22. Del-Ben CM, Machado VF, Madisson MM, Resende TL, Valério FP, Troncon LEDA. Relationship between academic performance and affective changes during the first year at medical school. Med Teach. 2013;35(5):404-10.

23. Gajalakshmi G, Kavitha U, Anandarajan B, Chandrasekar M. A study to analyze various factors contributing to stress in first year MBBS students during examination. Int J Biomed Adv Res. 2012;03:700-3.

24. Azari S, Baradaran HR, Fata L. Causes of academic failure of medical and medical sciences students in Iran: a systematic review. Med J Islam Repub Iran. 2015:29:1210-8.

25. Gupta S, Choudhury S, Das M, Mondol A, Pradhan R. Factors causing stress among students of a medical college in Kolkata, India. Educ Health Chang Learn Pract. 2015;28(1):92-5.

26. Census of Population and Housing. Department of Census and Statistics. Sri Lanka: Ministry of Finance and Planning; 2012.
Ready to submit your research? Choose BMC and benefit from:

- fast, convenient online submission

- thorough peer review by experienced researchers in your field

- rapid publication on acceptance

- support for research data, including large and complex data types

- gold Open Access which fosters wider collaboration and increased citations

- maximum visibility for your research: over $100 \mathrm{M}$ website views per year

At BMC, research is always in progress.

Learn more biomedcentral.com/submissions 